\title{
The Janus-Faced Nature of Philosophy of Science: Eleven Theses
}

\section{Marco Buzzoni ${ }^{1}$}

Received: 6 July 2021 / Accepted: 11 August 2021 / Published online: 15 October 2021

(C) The Author(s) 2021

\begin{abstract}
Elsewhere I have tried to provide the justification of both the irreducible (transcendental) distinction of science and philosophy and their inevitable (naturalistic) complementarity. Unlike empirical science, philosophy has no limit whatever as far as its possible objects are concerned. To say that there is no limit whatever to the possible objects of philosophy is to say that, strictly speaking, it has no object at all and must find its object outside itself, that is, in common sense knowledge and the natural and human sciences. Against the background of this conception, the paper argues that philosophy of science, as a critical reflection on common sense knowledge and the natural or human sciences, inherits from philosophy in general this two-faced Janus nature, which in the philosophy of science shapes the epistemological status of the discipline in an even more prominent way. To show this in detail, the paper enunciates eleven theses that derive from the intimate connection of unity and distinction that exists between philosophy of science on the one hand and the particular and specialized scientific knowledge on the other.
\end{abstract}

Keywords Philosophy of science $\cdot$ Kant's conception of philosophy $\cdot$ Science and philosophy $\cdot$ Naturalism $\cdot$ Professionalization in philosophy

\section{Introduction}

As has often been observed, the distinction between science and philosophy is relatively recent. If, on the one hand, there have been in the past philosophers who were also scientists, such as Aristotle, Leibniz, Descartes and Kant, on the other hand, and much more recently, there have been first-rate scientists who have also been philosophers of science of considerable value, such as Ernst Mach, Henri Poincaré, Arthur Eddington, Albert Einstein.

Marco Buzzoni

marco.buzzoni@unimc.it; buzzoni@mailbox.org

1 Department of Humanistic Studies, University of Macerata, Via Garibaldi 20, 62100 Macerata, Italy 
The history of science, moreover, seems to have shown that various problems, once considered philosophical, have been successfully solved by this or that particular science. This has often given rise to the suspicion that any philosophical problem can ultimately be removed from the endless war without winners or losers of philosophy, provided that it can be approached with the right scientific method. Philosophy, in this way, would be gradually deprived of its fundamental problems, losing scope and importance with respect to human culture in general.

This would seem to favour the most radical versions of naturalism and/or experimental philosophy, according to which there is neither difference between the methods of philosophy and science, nor qualitative difference or discontinuity between them (see e.g. Mach 1933; Quine 1960; Haug (ed) 2014, Fischer and Collins (eds) 2015). Few authors, however, even among the exponents of the most common forms of naturalism, have explicitly denied the fruitfulness or even the necessity of a close synergy or cooperation between science and philosophy, implicitly accepting Sellars' statement that we should not confound "the sound idea that philosophy is not science with the mistaken idea that philosophy is independent of science." (Sellars 1956: 301). But if this is not to remain mere wishful thinking, it is necessary to provide a justification for both the distinction and the need of cooperation between science and philosophy.

Elsewhere, starting from the investigation of the possibility and limits of thought experiments in philosophy, I have tried to provide a justification for both the irreducible distinctness of science and philosophy, as well as their inevitable complementarity (cf. xxxxxx). Rejecting Kant's material aspect of the a priori and drawing on its functional aspect, I maintained that it is possible to draw a distinction between philosophy and science that at once gives us a hint as to how to relate them to one another in such a way that they not only can, but must, cooperate. While science is intrinsically constituted by a conscious restriction of the field of its research, guided from time to time by this or that particular point of view, the distinctive trait of philosophy consists in its typically reflexive-transcendental attitude, which Kant expressed by saying that, instead of directing itself to objects-as common sense or scientific knowledge does-, philosophy reverses the direction or attitude of the scientific inquiry, and from objects it goes back to their conditions of possibility. From this reversing derives the unlimited scope of philosophy a parte objecti: there can be nothing about which philosophical reflection would be inappropriate, in principle. Unlike common sense or empirical science, philosophy has no limit whatever to its possible objects (which can include without any paradox philosophy itself).

However, the unlimited character of philosophical reflection is only one side of the Janus-Faced character of philosophy, the other being a limitation. To say that there is no limit whatever to the possible objects of philosophy is to say that, strictly speaking, it has no object at all. Here lies the main limitation of the most radical forms of naturalism. Exactly because philosophy has no particular domain of objects of its own, it must find its object outside itself, that is, in common sense knowledge or the natural and human sciences. Here lies the deepest insight of naturalism.

With this view as background, the paper argues that philosophy of science, as a critical reflection on natural or human sciences, inherits from philosophy in general this two-faced Janus nature, which in the philosophy of science shapes the 
epistemological status of the discipline in an even more prominent way. To show this in detail, the paper enunciates eleven theses that derive from the intimate connection of unity and distinction that exists between philosophy of science on the one hand and the particular and specialized scientific knowledge on the other.

The paper is organized as follows. In the first part of the paper (Sect. 2), after having dispelled a serious ambiguity in Kant's conception of the a priori, the already mentioned unity and distinction of science and philosophy is briefly outlined: the difference in principle between philosophy and science is such as to make the philosophy of science entirely dependent on this or that particular science as regards all its contents. Against the background of this main claim, Sect. 3 analytically develops the Janus-Faced character of the philosophy of science in eleven theses, which are finally summarized and listed in the conclusion.

\section{The Distinction Between Science and Philosophy from a Kantian Point of View}

Kant deserves credit for having attempted to draw a distinction between philosophy and science that gives us a hint as to how to relate them to one another in such a way that they not only can, but must, cooperate.

According to Kant, in asking what the nature and conditions of the possibility of knowledge are, philosophy "is occupied not so much with objects as with the mode of our knowledge of objects in so far as this mode of knowledge is to be possible a priori" (Kant KrV B 25, AA III, 43, 2-4 ${ }^{1}$ ).

Before seeing what consequences derive from this Kantian notion of the relationship between philosophy and science and specifically for philosophy of science, it is first necessary to mention and dissolve, albeit by very brief remarks, an ambiguity in Kant's conception of the a priori.

Kant subscribed to a view of the a priori that was denounced in the clearest terms, not only by the exponents of logical empiricism, but also by all the principal representatives of the philosophy of science, since the birth of the discipline at the end of the nineteenth century. This view, using Schlick's (and Husserl's) expression, portrayed the a priori as "material", that is, the a priori possesses particular contents (such as those expressed by the laws of the conservation of matter, the law of inertia, or the equality of action and reaction) that are unresponsive to critical revision by experience (see Schlick 1932). Kant would have conceived the categories as endowed with a determinate content and would have ascribed to them a constitutive role in knowledge in the sense that new and determinate cognitive contents may be discovered a priori by pure reason alone. In fact, as remarked more recently by Friedman, Kant tried to provide "a genuine metaphysical foundation" for that part of

\footnotetext{
1 Kant's works are cited according to the Academy Edition, though in the case of The Critique of Pure Reason I first give the original pagination of the 1787 (B) edition published by Meiner in 1998 and edited by Jens Timmermann. In this last case, quotations are from Kemp Smith's 1929 translation, if necessary revised in the light of the Paul Guyer and Allen W. Wood's 1998 Cambridge edition.
} 
Newton's Principia that Kant called the "pure part" (cf. Friedman 1992: 4 and 58), as well as an a priori foundation for theoretical forces such as those responsible for chemical attraction, cohesion, solidity and magnetism (cf. Friedman 2013: 25).

Now, this conception of the a priori was rejected by all the principal exponents of the philosophy of science, who pointed out that it was confuted by the history of science itself: relativistic physics, quantum physics, non-Euclidean geometry had demonstrated that there are no a priori principles endowed with particular contents and that are immune from revision by experience or from the adoption of different conventions (see e.g. Mach 1933: 458-459; Poincaré 1902: 64-65; Reichenbach 1920: 1-5; Bridgman 1927: 3-9; Lewis 1929; Popper 1935: 188; Dewey 1938; among the many recent authors, I confine myself to refer to Friedman 1992).

Strictly speaking, however, all these authors do not reject the material character of Kantian a priori: what they reject is just the claim that this character is also universal and necessary. More precisely, the material character of the a priori is accepted, though in a contingent and relativized form. This is also behind the famous idea of Thomas Kuhn being "Kant on wheels." (cf. Lipton 2003) Here, however, we want to explore the consequences of a formal or functional account of the a priori for the notion of philosophy of science, and I shall therefore only mention that the path these authors have taken is not viable, both for reasons of historical-philological accuracy and for reasons and for reasons to do with what we want from a theory of the a priori. On the one hand, to ascribe to Kant's a priori all the properties found in the empiricist conception of experience-relativity, variability, particularity, - means to betray both the letter and the spirit of Kant's philosophy. On the other hand, although a relativized conception of the a priori explains important aspects of the concrete dynamics of scientific change and practice (in a sense similar to that of the hermeneutic tradition), to abandon the universality and necessity of the a priori strips the concept of its power to answer many of the important questions Kant raised.

Because there is no space to discuss this issue here, and because I have argued elsewhere for this thesis, I confine myself to note that my reading moves in the opposite direction by retaining the universality and necessity of Kant's a priori, while subtracting from it any particular content, which instead comes only from experience. In fact, although Kant's a priori is not entirely free from material elements (and in this sense it has something in common with a contingent a priori), many interpreters, at least starting from Ernst Cassirer, have recognized that there is in Kant an opposite tendency to consider the a priori in a purely functional sense. It is in connection with this sense of the a priori that Kant develops some of the best-known tenets of his philosophy. He emphasises again and again that the unschematised categories have insufficient meaning to give us the concept of an object. He rightly says that categories without schemata and not applied to sense content are "merely functions of the understanding for concepts" and "may not [...] be employed," either empirically or transcendentally (cf. respectively KrV B 187, AA 139; KrV B 305, AA III 208. Cf. also KrV B 307-308, AA III 210, 31-35). That the "I think" is an empty idea, devoid of content is also the main point of Kant's criticism of the paralogisms of pure reason. Since the "I think" is the supreme formal condition of the possibility of experience, it cannot have a content of its own and 
must be conceived as a mere form or function: no manifold is given through the "I," taken as a simple representation (KrV B, §16, AA 110, 23-24: "durch das Ich als einfache Vorstellung ist nichts Mannigfaltiges gegeben"), and it cannot be regarded as being existing for itself. To mention a last point, it is in this connection that Kant says that the a priori, as the condition of experience, is always already in experience, but neither precedes nor follows experience-that is to say, it does not exist independently of experience (for more detail, see Buzzoni 2011a, 2013, 2018).

Now, it is precisely from this functional point of view of the a priori that I intend to return to the Kantian definition of philosophy, mentioned above. Once every material aspect of the a priori has been consistently rejected, Kant's claim that philosophy "is occupied not so much with objects as with the mode of our knowledge of objects in so far as this mode of knowledge is to be possible a priori" (Kant $\mathrm{KrV}$ B 25, AA III, 43, 2-4), may be expressed by saying that what is distinctive of philosophy is the fact that it reverses the direction or attitude adopted towards reality by common sense knowledge and its extension in the sciences. Instead of exploring some particular aspects of natural or cultural reality, the philosopher investigates our relation to them, that is, in Kant's parlance, the conditions of the possibility of the human faculty of knowing and morally evaluating natural or cultural reality.

Rejecting Kant's material aspect, and drawing on Kant's functional aspect of the a priori, we may develop a notion of philosophy of science according to which philosophy and science are different in principle and, at the same time, are related to one another in such a way that they not only can, but must, cooperate. In this way, one can reconcile two seemingly inconsistent positions: on the one hand, the transcendental Kantian definition of critical metaphysics as an analysis of the formal a priori conditions of the possibility of experience, and, on the other, the naturalistic rejection of any difference in kind between the particular methods of science and of philosophy.

On the one hand, here lies the most important qualitative distinction between science and philosophy. By reversing the direction or attitude adopted towards reality by scientific inquiry, philosophy gets a mode of inquiry or critical attitude so generalized as to act without a priori limits a parte objecti, that is, with respect to its possible subject-matter. Empirical sciences (and common sense knowledge) can only explore reality from particular points of view, which select particular aspects of reality, and necessarily neglect others: a mechanical phenomenon results from considering reality from a partial point of view, which takes into account only some properties of reality, such as force, mass and certain spatial and temporal relations. ${ }^{2}$

On reflection, it follows from this that each special science, since its characteristic concepts are bound to a particular point of view, has no means to answer the questions about the nature and conditions of its own kind of knowledge. For this reason, there are no such things as a physics of physics or a physics of philosophy; on the contrary, philosophy is not only capable of investigating the natural limits and conditions of the possibility of any cognitive activity or evaluative position, but can

\footnotetext{
${ }^{2}$ For more details, both from a historical and a systematic point of view, see Buzzoni (2016).
} 
summon itself for judgment before its own tribunal: it makes perfect sense to speak of a philosophy of philosophy (or meta-philosophy).

In other words, while science is intrinsically constituted by a conscious restriction of the field of its research, led by this or that particular point of view, there is nothing that can be excluded from philosophical critique. The unlimited openness of philosophy would only give rise to encyclopedic research, guided by the ideal of a complete erudition, if this distinctive trait of philosophy would not be connected with the trait that Kant expressed by saying that, instead of directing itself to objectsas empirical common sense or scientific knowledge does-philosophy reverses the direction or attitude of the scientific inquiry and goes back to their conditions of possibility. The possibility of this reversal of the point of view is, in the last analysis, the deepest root of the unlimited scope of philosophy a parte objecti, that is, of its ability to reflect and question any kind of experience (including the philosophical one).

An interesting and little-known anecdote about the life of the Italian philosopher Pasquale Galluppi illustrates this point nicely. One of his biographers tells us that Ferdinand II, who had little sympathy for the critical spirit of this philosopher, having seen him among the guests at a diplomatic party of the Duke of Montebello ambassador of France, expressed surprise at his presence. To which Galluppi replied: "Your Majesty, philosophy goes everywhere." ("Sire, la filosofia entra dappertutto") (Tulelli 1865: 20). No aspect of our lives can be fenced in and removed from the critical acids of philosophy, nothing can (and should) be alien to them.

On the other hand, however, the unlimited character of philosophical reflection, which I have so far placed in contrast to the limited and circumscribed character of common sense and scientific knowledge, is only one side of the coin, the other being a limitation. To say that there is no limit whatever to the possible objects of philosophy is to say that, strictly speaking, it has no object at all. This is hardly surprising: the rejection of any material content of the a priori leaves philosophy no domain of objects of its own, philosophy must find its object outside itself, that is, in the natural and human sciences (as well as in the humanistic disciplines and in everyday life).

Philosophy, on the one side, and the other expressions of human culture, on the other side, though distinct in principle, are so to speak designed to cooperate, since they are supplementary and inseparable. Given the purely functional nature of the a priori, philosophy could not break its connection with the rest of culture without cancelling itself. Philosophy is obliged by its very nature to open itself to what is different from itself, that is to say, to what lies outside it, to the different particular fields of human life, from which it draws its contents.

Herein lies the most convincing justification of the thesis held by most authors who have reflected on the relationship between philosophy and the sciences, but which, as far as I know, has ultimately remained merely a requirement, without philosophical justification. From our point of view, for example, Popper's thesis that philosophical problems "are always rooted in urgent problems outside of philosophy"_for example in mathematics, politics, religion, or social life_-and they "die if these roots decay" (Popper 1989: 71-72), acquires its full meaning and (as is not often the case with his views) can be fully accepted. 
But what about the particular methods? One may be inclined to think that the fact that philosophy reverses the attitude or direction of scientific inquiry entails important methodological differences between philosophy and science. This reversal is indeed intimately connected with the most obvious difference between philosophy and the empirical sciences. These latter fulfil the requirement, proper to all rational discourse, to testify as to how things really are, by means of the construction of what I would call an 'experimental machine' (or perhaps, expressed in the more fashionable terms of today, a "mechanism"), which concretely exemplifies the theoretical content of a claim about nature and its laws. The use of experiment is in the empirical sciences the main general strategy of checking reflection at every point of the argumentation. In scientific experiments, we test statements by the functioning of an 'experimental machine'.

Now, recourse to experiment is only indirectly possible for philosophy, which can have access to the contents of sensory experience only through common sense knowledge and the various special sciences and disciplines. However, the rejection of the material nature of the a priori, if consistently carried out, implies that, in spite of the opposite direction or attitude towards reality, there is no particular method or form of reasoning that is peculiar or restricted to philosophy. Thus, apart from the direction of inquiry (and the connected use of experiment), any other difference between science and philosophy can only arise from differences in the subject-matter dealt with, not from particular features that we might decide a priori.

There is no particular set of methods that could be called philosophical without fear of being contradicted by someone who could show their use in scientific fields (Kant himself pointed out a remarkable methodical analogy between transcendental argumentation and chemical investigation: cf. (KrV, B XX-XXI fn.; AA, III, 14 fn.). Feyerabend's thesis that there is no one method that can be said to have always led to success in the natural sciences, not only applies a fortiori to philosophy, but can only be based in the last analysis on a purely functional view of the a priori. Philosophers, too, use all the methods they are capable of devising to solve their concrete problems, and they all have only one feature in common, which cannot erase their irreducible diversity and multiplicity: not only that of trying to bring to light the internal contradictions in our discourses (the mere quest to eliminate contradictions would certainly not suffice to circumscribe 'the' philosophical method: even the scientist always tries to eliminate the internal inconsistencies in his own discourse), but the fact that this is done after reversing the direction of empiricalscientific investigation. ${ }^{3}$ For this reason, which is again intimately connected with the merely functional character of the a priori, philosophical argumentations are always negative, and their multiplicity can only derive from the empirical and multiple material or content whose conditions of possibility philosophy seeks to clarify

\footnotetext{
3 It may be objected that, according to Feyerabend, the last statement overlooks the fact that progress can also be made through the purposeful creation of inconsistencies and alternative hypotheses in our on-going discourse (I owe this suggestion to Mike Stuart). However, if the search for inconsistencies and alternative hypotheses is to have any meaning (e.g. that of fostering the progress of knowledge), it must be subordinated, in the final analysis, to the implicit assumption that we can thereby achieve greater coherence in knowledge that is relevant to us.
} 
(cf. Buzzoni 1990: 251-253, where I argued for this view against Heidegger; as is well known, this idea was later also defended by Marion, who has spoken of "negative certainties": see Marion 2010).

In this way, I fully accept the naturalistic thesis that there is no set of methods that are peculiar to philosophy, but at the same time I take a radically antinaturalistic position, since it is necessary to concede a relatively autonomous value to philosophy, without which, in the last analysis, even the claim to the truth-value of the various scientific discourses would remain without justification. ${ }^{4}$

\section{Eleven Theses on the Philosophy of Science}

With all the above as background, we are now in a position to address the problem of the epistemological and methodological status of the philosophy of science. The first, obvious but fundamental, consequence of what we have been saying is that the philosophy of science, understood as philosophical reflection on the particular empirical sciences (both natural and human), shares with philosophy in general a Janus-faced character: on the one side, it shares the inversion of the scientific stance towards objects and, therefore, both the unlimited scope of its critical attitude and a necessary reference to scientific contents lying outside itself. This point should now be made explicit and articulated in eleven theses, each of which describes an important feature of the philosophy of science. It goes without saying that what follows is no set of criteria that describes all and only the characteristics of philosophy of science, but rather important traits of the philosophy of science, which emerge, on the one hand, if a merely functional point of view about a priori knowledge is adopted, and, on the other, from the historical process of its self-understanding, from its birth to the present day.

1. From the point of view of a merely functional a priori, we may define philosophy of science as a critical reflection on the nature, conditions and limits of validity of the principles, procedures, commitments and results of science. It follows from this that there cannot be a valuable philosophy of science that does not possess a critical attitude towards science, since this attitude is unlimited in scope, and therefore must include science as its subject matter. This helps to explain what is otherwise difficult to explain in the history of human culture, that it was not in the positivist age that modern philosophy of science emerged as a relatively autonomous discipline, endowed with a clear historical and institutional continuity (on this last point, cf. Kraft 1968: 1), but only later, when many scientific disciplines fell into serious foundational crises and a strong reaction to positivist philosophy

\footnotetext{
${ }^{4}$ In order to forestall a possible objection, it is important to note that what has been said here about the relationship between philosophy and the empirical sciences is also correct for the formal disciplines (logic and mathematics), since they too, in my opinion, cannot do without an initial reference to experience, even if from time to time the special formal closure of their discourse protects them from refutation by new experiences. For some more details on this last point, see Buzzoni (2011b).
} 
had already widely spread. While positivism went so far as to ascribe to science an absolute value (just think of Comte's religion of science), at the end of the nineteenth century foundational crises led many scientists to reflect critically on the nature, conditions and limits of validity of their own knowledge, i.e., for them to become practitioners of philosophy of science.

2. The widespread (positivist) thesis according to which philosophy is destined to gradually abandon its fields of investigation to particular scientific disciplines, is strictly speaking false. One of the most interesting discussions of this thesis is Russell's in The Problems of Philosophy. On the one hand he concedes that the territory of philosophy became narrower and narrower as science took possession of parts of it, but on the other hand he partially withdraws this concession by making two points. First, "this is partly accounted for by the fact that, as soon as definite knowledge concerning any subject becomes possible, this subject ceases to be called philosophy, and becomes a separate science." (Russell 1912: 240) Second, there remain many questions that science is unlikely to be able to answer with its method and must probably "remain insoluble to the human intellect unless its powers become of quite a different order from what they are now." As an example, Russell refers to the question whether the universe has any unity of plan or purpose, or it is a fortuitous concourse of atoms (Russell 1912: 239-241; for a similar remark, see also James 1921: 10-11).

Russell's response is interesting, but not entirely convincing, as it is undermined by his ambiguous concession. The fact that in the past science has systematically taken over philosophical fields seems to make plausible the hypothesis that the process will continue and that what is called philosophy will become more and more a marginal residue of scientific progress. A limit in principle must be placed on the process of erosion of philosophy by science from the outset, otherwise it is arbitrary and dogmatic to claim that it will exist forever.

On the one hand, there is an important sense in which it is not true that, in the course of the history of human culture, new areas of knowledge were taken away from philosophy. If, as I have argued, philosophy has no domains of its own, there can be no gradual but inexorable process towards the end of philosophy. If philosophy has no domains of its own, no domain can be taken away from it. However, again from our point of view, there is another sense in which both points Russell made against the positivist thesis can be reinterpreted and accepted. In the first instance, new areas of knowledge were not taken away from philosophy, but from common sense knowledge (taking this term in a wide sense, including not only the most elementary knowledge related to our survival, but also that contained in legends and myths); in the second, he was right in saying that such a question as that concerning the unity of plan or purpose of the universe will probably never get a scientific answer (this was part of what I called his second point): he was right, if we take the question in its strictly philosophical sense, which relates to the meaning of our existence and our place in the universe. However, if we take the question in a more circumscribed sense, which is typical of everyday experience and scientific inquiry, Russell is also right in conceding that, as soon as there are empirically testable results, they are no longer regarded as philosophy, but rather as science. In fact, 
it was by developing and correcting in a systematic and controlled way methods that common sense already possessed (e.g., to console or comfort) that psychological disciplines could achieve therapies capable of distancing a person in distress from thoughts of suicide with a higher percentage of effectiveness than common sense, for example by rebuilding his or her sense of self-esteem, or of self-efficacy.

Moreover, although this operation was in the last analysis carried out independently by the particular empirical sciences, philosophy was not entirely alien to it. It is precisely the adoption of philosophy's attitude of an unlimited criticism that, in certain historical moments, made it possible to question long-standing, antecedent beliefs, thus opening new paths to controlled observations and experiments. But with this last remark, we have already anticipated our third thesis.

3. The unlimited scope of philosophical criticism is useful to science insofar as it is, at least in principle, a necessary premise for casting doubt on the fundamental assumptions on which a particular science is based. Although this in no way obliterates the principled distinction between science and philosophy of science, frontier scientific research addressing very general issues may be, de facto, very difficult to distinguish from philosophy of science. To conceive of a new scientific way to examine the natural or cultural world is tantamount to return, at least as a first necessary step, to the philosophical attitude, which refuses in principle to accept foundational concepts of any kind already established and taken for granted. Just as in the Greek myth, Antaeus renewed his strength whenever he touched the Earth (his mother), so scientific research, when it comes into contact with the limitless and unrestrained critique of philosophy, finds new paths and new energy to follow them.

It is a well-known fact that in the history of science, and especially during periods of foundational crisis, the distinction between science and philosophy of science became blurry. In fact, many protagonists of the debates on the foundations of physics (or mathematics)—such as Ernst Mach, Henri Poincaré, Albert Einstein, the fathers of quantum physics, etc. - are in fact considered both as scientists (or mathematicians) and philosophers. ${ }^{5}$

But also, the cases in which it is practically impossible to distinguish scientific from the philosophical activity do not call into question the distinction in principle defended here between science and philosophy of science, which is only one of attitude - towards objects vs towards our (theoretical-practical) relations to objects. This distinction is so important that it is no accident that Quine was not even aware that he was using it implicitly when formulating the central thesis of his naturalism, according to which philosophy "is continuous with science": the philosopher of science "may be a philosopher in point of professional affiliation, but a philosopher

\footnotetext{
5 Among the many authors who have stressed this point, see especially e.g., Kuhlmann and Pietsch (2012): 11, theses 2, 3 and 4. Despite the excellent empirical recognition both of the points of contact and of difference between physics and the philosophy of physics, in the last analysis the paper does not offer a satisfactory philosophical justification of them.
} 
with an interest in the special science concerned; or again, he may be an affiliate of the special science, but philosophical in attitude and motivation." (Quine 1970: 3-4; my italics).

4. Philosophy of science largely ceases to be fruitful as soon as a scientific problem becomes detailed and technical; conversely, the influence of the special sciences on philosophy of science is larger the more particular the scientific issues. As indicated in the third thesis, de facto philosophy of science influences the sciences all the more the more foundational are the questions addressed, because of the principled tendency of philosophy of science to relativize scientific knowledge and challenge its underlying assumptions. But, at the same time-and that is what matters now- the point of view here adopted makes it easy to understand how very particular questions, close to everyday experience, can be solved without significant contributions from philosophy of science, or, metaphorically speaking, this is why Thales fell into a well while gazing at the stars. What Russell said (against Marx) of the causal influence of society and the economy on scientific problems (Russell 1946: 813) — that it largely ceases to apply as soon as these latter become detailed and technical—may be repeated, mutatis mutandis, concerning the interaction between philosophy of science and the special sciences. The more the addressed issues are technical-particular, the more important the contents provided by the particular sciences become and, in the same proportion, philosophy of science seems to be-as an old Italian saying goes- "that thing with which and without which everything remains as it is" (or more freely: "that thing, with which and without which everything remains the same stitch" (quella cosa con la quale e senza la quale tutto resta tale e quale).

5. Both philosophers and scientists should contribute-and in fact have contributed-to the development of the philosophy of science, which should be regarded as the ideal meeting point of philosophy and the special sciences. On the one hand, it is evident that philosophers of science must know what they want to talk about: first, because a hypothetical pure philosopher-who fortunately, according to the fundamental thesis of this paper, cannot exist - could distinguish what is science from what is not science only through an arbitrary act of definition or, alternatively, through the uncritical acceptance of traditional assumptions. To say the same thing from a different but related point of view: because there is no disembodied (that is, non-operational) knowledge or, as Schopenhauer would have said, there is no "winged angel head without body" (Schopenhauer 1969, p. 99; English Transl. slight modified), there can be no pure philosopher of science, and those who would defend philosophy of science (and philosophy in general) in its absolute purity would only condemn it to complete insignificance. On the other hand, however, it would be naive to believe that scientists are the only subjects in a position to carry out a discourse on the nature of science. In the first place, hypothetical pure scientists - and they too, for a similar though opposite reason, fortunately cannot exist-would have to start their critical reflection either out of a zero of philosophy or uncritically assuming the implicit philosophy grounded in common-sense analysis of human experience. Moreover, those who rightly insist on the need to know directly some scientific content in order to practice 
philosophy of science, should not overlook the fact that today's specialization implies that scientists are laypeople, not only with respect to disciplines outside their expertise, but also with respect to the contents of their own discipline, of which they understand deeply only a comparatively small part.

6. Philosophy of science neither precedes nor follows scientific inquiry, but accompanies it. According to Kant, "transcendental philosophy", which consists in analysing the formal a priori conditions of the possibility of experience, "necessarily precedes all metaphysics" (cf. Kant, Prolegomena, AA IV, 279, 3-4). Contrary to this idea, however, philosophy of science cannot constitute a stand-alone preparatory work, which paves the way for further particular, scientific investigations. Since the philosophy of science, as philosophy, has no content of its own, it cannot develop, as Kant (at least in part) believed, a discourse on its own, but only and always a discourse in synergy with that of the particular sciences. And for the same reason philosophy cannot be final judge on empirical issues, but it should always and only accompany scientific (and common sense) judgments in the course of their making, as their self-critical moment. Philosophy of science comes neither, as Kant thought, before (what could it talk about?), nor, in Hegel's saying, in the twilight of evening (what did it do all day?): it is neither the founding science which Husserl conceived of, nor the justification of what has already been thought or done, but it is the self-critical moment that accompanies every scientific thinking and doing.

7. The efforts of Descartes, Kant, the neopositivist movement-just to name the most illustrious attempts-to ground philosophical reflection about science on the model of one particular science (logic, mathematics, physics, etc.), in order to attain the same or a degree of intersubjective agreement similar to it, are equivalent to the goal of pursuing the death of the philosophy of science. The goal is tantamount to pursuing the death of the philosophy of science because it would consist precisely in obliterating the inversion of the direction of enquiry in which philosophy consists. But the goal is unattainable for many reasons: first, the pretension of neopositivist philosophy of science to scrap history and start philosophy of science de novo and ab imis on the model of some particular scientific method is illusory because there is no absolute beginning, either in science or in philosophy; second, there is no method proper to either science or philosophy, and, once the philosophy of science has adopted the inversion of perspective proper to philosophical discourse, there is no way to prevent it from using any method that is appropriate to the object of its enquiry; third, to cancel the inversion of enquiry characteristic of the philosophy of science is impossible without implicitly assuming it: it applies to philosophy of science what Étienne Gilson said about philosophy in general, that it always buries its undertakers. It is no accident, therefore, that these attempts-as e.g., emphasized by Marcos 2021 - have in fact given only a new impulse to the philosophy of science, contributing to deeper philosophical reflection on science.

8. Although under inverted perspectives, both science and philosophy of science strive towards the common ideal limit of modifying, or even rejecting, empiricalscientific concepts and hypotheses on the basis of experience, that is, on the basis of operational-experimental interventions on reality. As for science, all 
empirical concepts and hypotheses, even while they are still in our minds, already possess an intrinsic technical-operational reference to experience, and have to be conceived of as in principle wholly translatable into real processes. Without this assumption, we abandon science and are left with the play of imagination. This is just to say that empirical science must be in principle 'completely public'; it must, that is, be reducible to actions that are experimentally reproducible and therefore intersubjectively testable. Whatever resists this possible reduction thereby shows itself to be an arbitrarily introduced factor (which may be only temporarily legitimate, if we have some reasons to think that it will disappear in the final result) (for some more details on this controversial point, see Buzzoni 2016).

Now, this is one of the most important goals of philosophy of science, though pursued under its inverted perspective. Although strictly speaking the solution of any conflict between scientists must be resolved using scientific methods and therefore by scientists as scientists (or by philosophers as scientists), part of the task of scientists is to exercise critical thinking not only about the content of their knowledge, but also about their own methodical procedures for accessing reality. It is in this respect that philosophers of science can offer their special help to scientists, strengthening the already self-critical and self-correcting character of science. As already said, philosophy of science, going back to the conditions of possibility of science, bring to the light the relativity of scientific concepts to certain fundamental assumptions. But no matter how difficult it can be, scientific fundamental assumptions should also ultimately be related to empirical reality and should therefore be susceptible to modification or, even, rejected on the basis of experience. In this way, philosophers of science can help scientists in the task of distinguishing, even if only in relation to the present state of scientific inquiry and as a never-ending quest, science from non-science. We may conclude that, albeit adopting inverted perspectives, both philosophy of science and science strive towards this common ideal limit.

\section{Claims made in philosophy of science can essentially be assessed in two different} ways, either from the side of the form (lack of internal coherence) or from the side of the content (with respect the empirical features of scientific inquiry).

As already Kant rightly noted, a serious difficulty in evaluating philosophical claims arises

from the fact that, unlike the natural sciences, one cannot test hypotheses by experimenting with the relevant objects (cf. KrV, B XX-XXI fn.; AA, Ill, 14 fn.). What else could we rely on in distinguishing true arguments from false ones in the philosophy of science? The main point of this paper suggests that the more general criterion of evaluation is that of coherence, of which two forms ought to be distinguished, depending on whether it is considered from the point of view of the form or from the point of view of the content, that is, either as internal coherence or as coherence with the disciplines whose nature, conditions and limits of validity the philosophy of science seeks to clarify. In the first sense we can evaluate claims in philosophy of science with respect to their internal coherence. 
Therefore, an important regulative ideal for philosophy of science should consist in being interwoven with coherent concepts and hypotheses and in avoiding inconsistencies or difficulties that alternative conceptions run into.

However, because any philosophical reflection must look for contents outside itself, it is also possible to criticise claims made in philosophy of science from the side of their content. From this side, claims made in philosophy of science should be adequate with respect to their subject-matter and should not mistakenly assume characteristics of the subject-matter they refer to. Therefore, for example, a claim can be criticised because its concepts or hypotheses are contested within the scientific community, or because it misinterprets certain scientific hypotheses, overlooks hypotheses long present in the scientific discourse, or generalises certain isolated and not yet theoretically well understood evidence, and so on.

The best example is perhaps Thomas Kuhn's well-known objections to Popperian philosophy of science. According to Kuhn, the Popperian image of science is biased because it does not correspond to actual scientific practice as exhibited by the history of science. Popper's conception of science as "permanent revolution" only applies to the "occasional revolutionary parts" of science, but historical investigation shows that revolutionary episodes, though they do happen, are rare: usually, scientists do not try to criticise and question scientific theories at all, but carry out "normal science", that is, "routine" work (Kuhn 1970: 6).

It is important to note that, strictly speaking, the second way of criticizing philosophy of science is not purely philosophical, because it is based on contents drawn from the particular empirical sciences (in Kuhn's example, the history of science). A strictly philosophical criticism (what we have called criticism from the side of the form), as Kant had already noted, does not admit or tolerate direct recourse to observation or experiment. This is sufficient to explain the different degree of agreement that can be reached, on the one hand, in the sciences, where the use of methodically controlled experiment is possible, and, on the other, in philosophy of science, where this use is not (directly) available. Williamson argued against Weinberg 2009 that we have made some progress also in philosophy, but, as far as this point is concerned, it is difficult to admit that the situation has changed radically since Kant's Preface to the second edition of his Critique of pure reason, where he compared "metaphysics" to "a battle-ground [...] in which no participant has ever yet succeeded in gaining even so much as an inch of territory, not at least in such manner as to secure him in its permanent possession." (KrV B xv, AA, 11, 14-18) The main thesis of this paper, together with our distinction between a critique from the point of view of form and one from the point of view of content, allows us here to shed some new light on this discussion. As already said, philosophical thinking has a radically negative status, and the greatest strength of philosophical criticism-even if it is directed against empirical knowledge-is when it highlights internal contradictions or inconsistencies. Conversely, when it comes to positive argumentation, it is hard to deny that the philosophy of science is far less persuasive than the very scientific disciplines on which it seeks to critically reflect; for example, contrary to Williamson's claim (cf. Williamson 2009: 473-474), in spite of all the efforts to introduce methods of peer review into philosophy, a little experience with referees in philosophy shows that they are not to be equated with the use of double-blind methods in science and that it 
remains true that disagreement about fundamentals is a phenomenon intimately connected to the very nature of philosophy.

This double perspective on the assessment problem in philosophy offers a more satisfactory answer than that often offered by many authors in the very large discussion going on right now about the nature of philosophical progress (for a complex and well-informed examination of this point, which however only captures one of the two sides of the assessment problem considered here, see especially Hannon and Nguyen, manuscript). On the one side (that of form), in fact, the perspective here defended allows for an evaluation of progress quite similar to that which applies to every other sphere of human culture, namely by discussing and evaluating the degree of overall coherence (today someone would perhaps say: of the objectual understanding) of our past philosophical endeavours in relation to the problems that occupy us at a particular historical-cultural moment. (This is the hermeneutic dimension of any sphere of the human culture, including natural science: for more detail Buzzoni 1995 ch. 3). On the side of the content, however, there is a second criterion for assessing philosophical progress. It derives from the fact that, as we have argued here, philosophy has no content of its own, and must therefore each time go out of itself to carry out its own critical reflection on every sphere or aspect of our (cognitive or practical) relationship with the world. In the case of the philosophy of science, therefore, there is progress whenever the disciplines on which philosophy reflects make some progress (sometimes, as we know, also thanks to philosophical reflections on some aspects concerning them). To put it somewhat paradoxically, but perhaps effectively: a hypothetical philosophy of physics that ignored the important scientific acquisitions that have taken place since Newton (which fortunately does not exist) would be a philosophy of science hopelessly dated and defective.

10. Philosophy of science is not specialized knowledge in the sense of the empirical sciences, its concept of expertise is in principle different, and an excessive professionalization of philosophy is at odds both with its unlimited critical openness and with its necessary reference to content placed outside itself. The unlimited critical openness of philosophy implies that, unlike the fields of empirical research, professionalization in philosophy of science is possible only in a broad sense. Given the lack of a content of its own, professionalization of philosophy of science (and of philosophy as such) risks making it a speciality locked in an ivory tower, that is, empty and sterile. Philosophy of science, as a philosophical reflection, cannot remain locked in itself-it must reach out to that which is not philosophy. The same question about its nature would be condemned to insignificance if it were exhausted in a narcissistic obsession about itself: this question is justified only to the extent that the answer takes the form of the general need to go beyond itself. That is the fundamental reason that, as 
has been noted, an excessive closure and professionalization of philosophy "is compatible at a certain point with the absence of philosophy," and can lead to "a certain complacency, even a certain blindness, in the face of what remains philosophically important."6

11. The philosophy of science, no less than philosophy in general, cannot be content with interpreting the world, but should also try to improve it. A philosophical reflection on science is today no academic luxury, but the objective need of our culture to clarify the possibilities and the limits (theoretical as well as practical) of science as one of the most important factors conditioning our natural and cultural environment.

From the dawn of science until the end of the nineteenth century, scientific progress was synonymous with civil and human progress, and from Bacon's utopia of a New Atlantis to the Enlightenment dream of a humanity entirely illuminated by the light of reason, science was considered an essential factor for a better and fairer world. Two world wars, Hiroshima, Seveso, Chernobyl, the risk of global pollution that can no longer be controlled, the hole in the ozone layer and the fear of a climate catastrophe, and in short, to quote a poet, the extreme possibility of "the earth without us" (Guerrini, p. 92), have destroyed this optimistic and naive vision not only of science but also of any critical reflection on it. It has therefore been rightly noted that, compared to the narrow vision of the philosophy of science imposed by logical empiricism for decades, we need a new concept of philosophy of science, which must not only recur to epistemology, formal logic and philosophy of language, but also to ethics, social and political philosophy, axiology, etc. and the social environment that surrounds it (see e.g., in this issue, Agazzi 2021).

At first sight it might seem that this is hardly compatible with the view here propounded, since the idea that philosophy of science is a reflection that reverses the direction or attitude of the scientific inquiry, and from objects goes back to their conditions of possibility, seems to make it, in the last instance, a purely theoretical analysis. This would be a grave misunderstanding, and against it we must urge that the conditions of possibility that a philosophical discourse on science must clarify are always conditions both of thinking about and of intervening on the objects that surround us. As already said, unlike empirical science, philosophy of science, as a philosophical reflection on science, does not put questions to nature, but questions about our (historically changing) methodical and systematic mode of organizing, interpreting, and evaluating what we call the external world. It is therefore no accident that the term "philosophy of science" is both used as a synonym of theory of knowledge or epistemology and, quite legitimately, also with a broader meaning, which includes the problems of the relations between science and other spheres of human culture, such as politics, morality, religion, art, etc. It is no accident, since it

\footnotetext{
${ }^{6}$ Stroud (2018, p. 17); see also the similar opinion by Harries (2001, p. 61). This view underlies one of the leading trends in the philosophy of science, the so-called "practical turn", which has also given rise to the formation of special philosophical societies (such as e.g. the "Society of Philosophy of Science in Practice": https://www.spsp2020.org/).
} 
is another way of expressing the Janus-faced nature of philosophy and philosophy of science. Precisely because of the unlimited critical attitude that it shares with philosophy in general, philosophy of science should undertake a critique of the contents of the particular sciences, natural as well as human, assessing their theoretical and ethical-practical value also for the culture in which they are embedded. Thus, philosophy of science must reflect both on the conceptual-scientific apparatus by means of which we gain access to the natural world and on the ethical-practical commitments that this access necessarily brings with it. In this way the philosophy of science contributes to the practical goal of a life worth living. For this reason the philosophy of science, no less than philosophy in general, cannot be content with interpreting the world, but should also try to improve it.

\section{Conclusion}

Starting from a conception of the relationship between philosophy and the particular empirical sciences that I developed elsewhere, I briefly outlined an account of the philosophy of science that reconciles a methodological naturalism that does not admit any difference in kind between the methods of science and of philosophy with the thesis of a principled difference between science and philosophy of science. Philosophical reflection overturns the direction of the investigation proper to the particular sciences and to the empirical knowledge of common sense and critically reflects not directly on the objects, but indirectly on our relationship-theoretical no less than ethical, aesthetic, etc.- - towards them. On the one hand, this explains the unlimited critical nature of philosophy, as there is no reality that can escape its critical investigation; on the other hand, this implies an important limitation: that philosophy does not have, strictly speaking, any object of its own, thus having to draw all contents from common sense knowledge and the particular empirical sciences, natural or human.

Against the background of this conception, the paper argued that philosophy of science, as a critical reflection on particular natural or human sciences, inherits from philosophy in general its two-faced Janus nature, which in the philosophy of science shapes the epistemological status of the discipline in an even more prominent way. To show this in detail, the paper enunciated eleven theses that derive from the intimate connection of unity and distinction that exists within the philosophy of science between philosophy on the one hand and the particular and specialized scientific knowledge on the other. From what we have been saying, the characteristic marks of philosophy of science might be listed as follows:

1. From the point of view of a merely functional a priori, we may define philosophy of science as a critical reflection on the nature, conditions and limits of validity of the principles, procedures, commitments and results of science. It follows from this that there cannot be a valuable philosophy of science that does not possess a critical attitude towards science. 
2. The widespread (positivist) thesis according to which philosophy is destined to gradually abandon its fields of investigation to particular scientific disciplines, is strictly speaking false. If, as I have argued, philosophy has no domains of its own, in an important sense no domain can be taken away from it.

3. The in principle unlimited scope of philosophical criticism is useful to science insofar as it is, at least in principle, a necessary premise for casting doubt on the fundamental assumptions on which a particular science is based. Although this in no way obliterates the principled distinction between science and philosophy of science, frontier scientific research addressing very general issues may be, de facto, very difficult to distinguish from philosophy of science.

4. Philosophy of science largely ceases to be fruitful as soon as a scientific problem becomes detailed and technical; conversely, the influence of the special sciences on philosophy of science is larger the more particular the scientific issues are.

5. Both philosophers and scientists should contribute - and in fact have contributed - to the development of the philosophy of science, which should be regarded as the ideal meeting point of philosophy and the special sciences.

6. Philosophy of science neither precedes nor follows scientific inquiry, but accompanies it.

7. All the efforts to ground philosophical reflection about science on the model of one particular science (physics, logic, mathematics, etc.), in order to attain the same or a degree of intersubjective agreement similar to it, is equivalent to the goal of pursuing the death of the philosophy of science.

8. Although under inverted perspectives, both science and philosophy of science strive towards the common ideal limit of modifying, or even rejecting, empiricalscientific concepts and hypotheses on the basis of experience, that is, on the basis of operational-experimental interventions on reality.

9. Claims made in philosophy of science can essentially be assessed in two different ways, either from the side of the form (lack of internal coherence) or from the side of the content (with respect the empirical features of scientific inquiry).

10. Philosophy of science is not specialized knowledge in the sense of the empirical sciences, its concept of expertise is in principle different, and an excessive professionalization of philosophy is at odds both with its unlimited critical openness and with its necessary reference to content placed outside itself.

11. The philosophy of science, no less than philosophy in general, cannot be content with interpreting the world, but should also try to improve it. A philosophical reflection on science is today no academic luxury, but the objective need of our culture to clarify the possibilities and the limits (theoretical as well as practical) of science as one of the most important factors conditioning our natural and cultural environment.

Acknowledgements This work was supported by the Italian Ministry of Education, University and Research through the PRIN 2017 program "The Manifest Image and the Scientific Image" prot. 2017ZNWW7F_004. Special thanks to Mike Stuart, who read a draft of this article and provided helpful comments and suggestions. 
Open Access This article is licensed under a Creative Commons Attribution 4.0 International License, which permits use, sharing, adaptation, distribution and reproduction in any medium or format, as long as you give appropriate credit to the original author(s) and the source, provide a link to the Creative Commons licence, and indicate if changes were made. The images or other third party material in this article are included in the article's Creative Commons licence, unless indicated otherwise in a credit line to the material. If material is not included in the article's Creative Commons licence and your intended use is not permitted by statutory regulation or exceeds the permitted use, you will need to obtain permission directly from the copyright holder. To view a copy of this licence, visit http://creativecommons.org/licen ses/by/4.0/.

\section{References}

Agazzi E (2021) The multiple aspects of the philosophy of science. Axiomathes, S.I. Epistemologia (this issue)

Bridgman PW (1927) The logic of modern physics. MacMillan, New York

Buzzoni M (1990) Zum Begriff der Person: Person, Apriori und Ontologie bei Heidegger und Ricoeur. In: Papenfuss D, Pöggeler O (eds) Zur philosophischen Aktualität Heideggers. Bd. 2: Im Gespräch der Zeit, pp. 227-253. Klostermann, Frankfurt a.M.

Buzzoni M (1995) Scienza e tecnica. Teoria ed esperienza nelle scienze della natura. Studium, Rom

Buzzoni M (2011a) Kant und das Gedankenexperiment. Deut Z Philos 59:93-107

Buzzoni M (2011b) On mathematical thought experiments. Epistemol Italian J Philos Sci 39:5-32

Buzzoni M (2013) On thought experiments and the Kantian a priori in the natural sciences. A Reply to Yiftach Fehige. Epistemologia 36:277-293

Buzzoni M (2016) Mechanisms, experiments, and theory-ladenness: A realist-perspectivalist view. Axiomathes 26:411-427

Buzzoni M (2018) Kantian accounts of thought experiments. In: Brown JR, Fehige Y, Stuart M (eds) The Routledge companion to thought experiments. Routledge, New York, pp 327-341

Buzzoni M (2019) Thought experiments in philosophy: A neo-Kantian and Experimentalist point of view. Topoi 38:771-779

Dewey J (1938) Logic: The theory of inquiry. Holt, Rinehart \& Winston, New York

Fischer E, Collins J (eds) (2015) Experimental philosophy, rationalism, and naturalism. Rethinking philosophical method. Routledge, London

Friedman M (1992) Kant and the exact sciences. Harvard University Press, Cambridge

Friedman M (2013) Kant's construction of nature. A reading of the metaphysical foundations of natural science. Cambridge University Press, Cambridge

Guerrini A (1978) L'età di ferro. Mondadori, Milan

Hannon M, Nguyen J (2021) (manuscript). Understanding Philosophy. https://philpapers.org/rec/HANUP

Harries K (2001) Philosophy in search of itself. In: Ragland CP, Heidt S (eds) What is philosophy. ValBallou, Binghampton, pp 47-73

Haug MC (ed) (2014) Philosophical methodology: the armchair or the laboratory? Routledge and Kegan Paul, London

James W (1921) Some problems of philosophy. Longmans, London

Kraft V (1968) Der Wiener Kreis, 2nd edn. Springer, Berlin

Kuhlmann M, Pietsch W (2012) What Is and Why Do We Need Philosophy of Physics? J Gen Philos Sci 43:209-214

Kuhn TS (1970) Logic of Discovery or Psychology of Research? In: Lakatos A, Musgrave A (eds) Criticism and the Growth of Knowledge. Cambridge University Press, Cambridge

Lewis CI (1929) Mind and the World Order. Dover, New York

Lipton P (2003) Kant on wheels. Social Epistemology: A Journal of Knowledge, Culture and Policy 17: 215-219

Mach E (1933) Die Mechanik in ihrer Entwickelung, 9th edn. Brockhaus, Leipzig

Marcos A. 2021. Philosophy of Science and Philosophy: the long flight home. Axiomathes, S.I. Epistemologia (this issue)

Marion J-L (2010) Certitudes négatives. Figures, Paris

Poincaré H (1902) La science et l'hypothèse. Flammarion, Paris 
Popper KR (1935) Logik der Forschung. Springer, Wien

Popper K.R. 1989. Conjectures and Refutations. $5^{\text {th }}$ revised ed., Routledge \& Kegan Paul, London

Quine WVO (1960) Word and Object. M.I.T Press, New York

Quine WVO (1970) Philosophy of language, philosophical progress in language theory. In: Kiefer HE,

Munitz MK (eds) Language, Belief, and Metaphysics. State University of New York Press, New York, pp 3-18

Reichenbach H (1920) Relativitätstheorie und Erkenntnis a priori. Springer, Berlin

Russell B (1912) The problems of philosophy. Williams and Norgate, London

Russell B (1946) History of Western Philosophy. Allen \& Unwin, London

Schlick M (1932) Gibt es ein materiales Apriori? In: Wissenschaftlicher Jahresbericht der Philosophischen Gesellschaft an der Universität zu Wien. Verlag der Philosophischen Gesellschaft, Wien 1932, pp. 55-65.

Schopenhauer A (1969) The World as Will and Representation (vol. 1). Dover, New York (Transl. E. F. J. Payne).

Sellars W (1956) Empiricism and the Philosophy of Mind. In: Feigl H, Scriven M (eds) Minnesota Studies in the Philosophy of Science, vol I. University of Minnesota press, Minneapolis, pp 253-329

Stroud B (2018) Seeing, Knowing. Oxford University Press, Oxford, Understanding. Philosophical Essays

Tulelli PE (1865) Intorno alla dottrina ed alla vita politica del barone Pasquale Galluppi. Stamperia della R. Università, Napoli

Williamson T (2009) Replies to Ichikawa, Martin and Weinberg. Philos Stud 145:465-476

Publisher's Note Springer Nature remains neutral with regard to jurisdictional claims in published maps and institutional affiliations. 